\title{
Potential of ribonuclease-sinthesizing plant growth promoting rhizobacteria in plant defence against viruses
}

\author{
G.F. Burkhanova*, A.V. Sorokan, V.U. Alekseev, A.A. Mazitova, I.V. Maksimov \\ Institute of Biochemistry and Genetics - Subdivision of the Ufa Federal Research Centre of the Russian Academy of Sciences, Ufa, Russia
}

DOI 10.18699/ICG-PlantGen2019-24

(c) Autors, 2019

*e-mail: guzel_mur@mail.ru

\begin{abstract}
Viruses cause epiphytotics on all major cultures of agronomic importance, representing a serious danger to global food security. As strictly intracellular pathogens, they cannot be controlled chemically and prophylactic measures consist mainly in the destruction of infected plants and excessive pesticide applications to limit the population of vector organisms. An alternative antiviral strategy is associated with the use of microbial enzymes, which are less toxic and are readily decomposed without accumulation of harmful substances. Plant-growth promoting microorganisms (PGPR), especially endophytic strains, or their communities can promote plant defence against viral diseases via producing ribonucleases, which are capable of degrading viral RNA.
\end{abstract}

Key words: plant virus; PGPR; endophyte; ribonuclease; resistance.
Viruses cause epidemics in all major crops, threatening global food security. The development of efficient and durable resistance able to withstand viral attacks represents a major challenge for agrobiology. Currently, viruses cannot be controlled with chemical pesticides, since known antiviral compounds are hazardous to people's health, such as teratogenic ribaverine (1, beta-D-ribofuranosyl-1,2,4-triazole3-carboxamide), which significantly reduced TSWV content in tomato and tobacco plants, via blocking RNA-replication. At present, practical control measures include monitoring and chemical control of the vector causing the viral disease to reduce yield losses. In addition, viral resistance breeding is limited by the absence of resistance genes. Transformationbased genetic engineering is restricted due to a large amount of time required for crossing in the field and environmental safety issues in many countries (Paudel, Sanfaçon, 2018). The application of systemic acquired resistance with non-specific elicitors or PGPR to manage viral diseases was recognized as a promising tool (Lee, Rui, 2016).

Hypersensitive response (HR), systemic acquired resistance (SAR), and elaboration of the gene-for-gene resistance response are contemporary immune response paradigms that were discovered more than 50 years ago (Mandadi, Scholthof, 2013). Accumulation of PR proteins is an integral component of innate immune responses in plants during viral attack. The PR-10 family, plant RNAses, are ubiquitous proteins that have been identified in a number of dicot and monocot plant species. They are small, slightly acidic and resistant to proteases. PR-10 proteins are classified as intracellular PR (IPR) proteins and are present in the cytoplasm because they lack signal peptide (Jain, Kumar, 2015). Thus, phosphorylation leads to enhanced ribonucleolytic activity against viral RNAs upon Tobacco mosaic virus (TMV) infection showing direct involvement of ribonucleolytic activity in plant defense (Park et al., 2004). For buckwheat varieties with different resistance to the Buckwheat burn virus (BBV), a positive correlation between resistance to virus and RNase activity was shown, the authors have analyzed two varieties, Roksolana and KaraDag (Sindarovska et al., 2014). Trifonova et al. (2018) have proposed to use of the level of RNase activity in potato leaves as a selective marker for resistance to viruses.

Interestingly, Loring (1941) has shown, for the first time, the reversible inactivation of TMV by exogenous crystalline ribonuclease and a decrease in the number of lesions on Nicotiana glutinosa and Phaseolus vulgaris leaves infected with RNAse-treated TMV. However, there is not a single preparation based on this technology, probably due to the lack of a "delivery agent". Transformation-based genetic engineering was the first step towards solving this problem. Thus, approximately one third of tobacco transgenic lines containing betasatellite DNA associated with cotton leaf curl disease and barnase of $B$. amiloliquefaciens gene constructs were shown to be completely resistant to Tomato leaf curl virus (TLCV) infection. There was no expression of barnase in the absence of TLCV, but upon infection of the cell with the virus, release of the betasatellite/split barnase cassette as a replicating molecule results in the reconstitution and expression of an active barnase gene and the destruction of the infected cell (Pakniat-Jahromy et al., 2010).

Thus, transgenic soybean lines constitutively expressing the double-strand RNA specific ribonuclease gene PAC1 from Schizosaccharomyces pombe exhibited less severe symptoms and enhanced resistance to Soybean mosaic virus (SC3 SC7, SC15, SC18 and SMV-R strains), and three isolates of Bean common mosaic virus (BCMV), Watermelon mosaic virus (WMV), and Bean pod mottle virus (BPMV) relative to WT plants (Yang et al., 2019).

Ribonuclease Cas13a was shown to provide immunity to a bacteriophage in Escherichia coli by interfering with the MS2 lytic ssRNA phage (Qi et al., 2013). CRISPR/Cas13a showed interference against green fluorescent protein (GFP)expressing TuMV in lines of Nicotiana benthamiana. Northern blots showed a clear reduction in the accumulation of the TuMV-GFP RNA genome using the crRNAs targeting HC-Pro or GFP2, indicative of targeted degradation of the TuMV-GFP genomic RNA via CRISPR/pCas13a (Aman et al., 2018).

Sugawara et al. (2016) generated transgenic Nicotiana tabacum plants expressing heterologous bovine pancreatic RNase. 
Higher RNase levels in the apoplast resulted in increased resistance to both CMV (Bromoviridae, Cucumovirus) and TMV (Virgaviridae, Tobamovirus), indicating a role of RNAhydrolyzing enzymes in non-specific plant antiviral response.

Research over the past decades provided substantial advances in the field of plant-miccrobe and plant-virus interactions. Remarkably, the advent of studies of plant interactions with plant-growth promoting rhizobacteria (PGPR), in particular, endophytic strains, has recently offered new strategies exploitable in the field.

So, it suggests the need for a search for biocontrol agents that combine the follow properties: a) integrated biocidal activities to spreading harmful organisms; b) the ability to induce plant immune reactions; c) environmental safety. Therefore, plant growth-promoting bacteria (PGPB), in particular, endophytic PGPB, which belong to a beneficial and heterogeneous group of microorganisms, are of great interest (Khalaf et al., 2018; Abdalla et al., 2017).

Endophytic microorganisms live within the tissues of plants without causing any symptoms of disease. Endophytes should be a treasured biological resource for plant protection against pathogens and pests. Bacterial endophytes have an advantage over bacteria inhabiting the rhizo- or phyllosphere, since living within a plant's tissues represents an opportunity to always be in "contact" with the plant's cells and, therefore, to more readily exert a direct beneficial effect on plant hosts, and to reduce the influence of the environmental conditions on PGPB. It was shown (Araújo et al., 2015) that a number of Bacillus strains have fungicidal, insecticidal, aphycidal (Araújo et al., 2015; Yang et al., 2017) and growth-promoting activities (Pieterse et al., 2014), synthesize antibiotics and biosurfactants (De Vleesschauwer, Höfte 2009), promote induced systemic resistance (ISR) against pathogens and pests (Rashid, Chung 2017). There is a wealth of data on endophyte influence on plant viability, and the most recent are investigations of the problem of artificial plant microbial community on the basis of growth-promoting bacteria (Moronta-Barrios et al., 2018).

The PGPR Bacillus polymixa and Pseudomonas fluorescens mix with chitosan application delayed symptom development and reduced disease severity as well as the titer of Squash mosaic virus (SqMV) at the generative phase of cucumber plants (Firmansyah et al., 2017). The mixture containing B. amyloliquefaciens IN937a, B. pumilus SE34 and B. pumilus T4 promotes tomato and papaya plants' resistance to Tomato chlorotic spot virus (TCSV) and Papaya ringspot virus (PRSV-W), respectively (Abdalla et al., 2017).

For instance, Piriformospora indica (Hymenomycetes: Basidiomycota), an endophytic root-colonizing fungal species, has been shown to repress Pepino mosaic virus (PMV), which is found widely in tomato greenhouses in many parts of the world, especially at high light intensities (Fakhro et al., 2010). Replication of Iris yellow spot virus (IYSV) was significantly reduced in endophytic fungus Hypocrea lixiicolonized onion plants as compared to endophyte free plants (Muvea et al., 2018). Arabidopsis thaliana ecotype columbia plants (Col-0) treated with S. marcescens 90-66 and B. pumilis strain SE-34 significantly reduced the symptom severity caused by Cucumber mosaic virus (CMV) (Ryu et al., 2004).
In a study by Harish et al. (2008), two endophytic bacterial strains belonging to Bacillus spp. (EPB22) and Pseudomonas spp. (EPB5) promoted banana resistance against Banana bunchy top virus (BBTV).

Bacteria, fungi and their metabolites can bind and destruct viral particles directly, through the synthesis of proteases, nucleases and lipopeptides. To date, 20 extracellular nucleases which have been characterized for Bacillus spp. B. amyloliquefaciens, B. pumilus and B. licheniformis produce extracellular RNAses, called 'barnase', 'binase' and 'balifase', respectively (Ulyanova et al., 2011, 2016; Ilinskaya et al., 2018). Among endophytic bacteria which were isolated from plants of the family Cucurbitacea, $73 \%$ of Bacillus spp., $27 \%$ of Paenibacillus spp., $30 \%$ of Enterobacteriaceae, all isolates of Cronobacter, Pantoea, Microbacterium and Staphylococcus showed RNAse activity (Khalaf, Raizada, 2018).

Bacillus pumilus ribonuclease possesses antiviral activity against plant RNA-viruses RCMV (Red clover mottle virus), PVX (Potato virus X) and AMV (Alfalfa mosaic virus). The maximum inhibitory effect against actively replicating viruses is observed when plants are treated with the enzyme at a concentration of $100 \mathrm{ug} / \mathrm{ml}$ prior to infection (Sharipova et al., 2015).

Bacillus cereus ZH14, which was isolated from Chinese Anxi oolong tea, secreted antiviral substances having 94.2\% virus inhibition when the bacterial culture filtrate and TMV extract were mixed at a ratio of 1:1 and had the ability to degrade ribonucleic acid (Zhou et al., 2008).

Thus, the search for endophytic microorganisms that can produce RNAses directly in plant tissues is a promising area of the development of the set of activities required to for defending plants against viral diseases.

\section{References}

Abdalla O., Shagufta B., Shouan Z. Application of plant growth-promoting rhizobacteria to control Papaya ringspot virus and Tomato chlorotic spot virus. Arc. Phytopathol. Plant Protect. 2017;50:1. DOI 10.1080/03235408.2017.1352248.

Araújo E.O. Rhizobacteria in the control of pest insects in agriculture. Afr. J. Plant Sci. 2015;9(9):368. DOI 10.5897/AJPS2015.1318.

De Vleesschauwer D., Höfte M. Rhizobacteria-induced systemic resistance. Adv. Bot. Res. 2009:51;223. DOI 10.3389/fpls.2017.01816.

Fakhro A., Andrade-Linares D.R., von Bargen S., Bandte M., Büttner C., Grosch R. et al. Impact of Piriformospora indica on tomato growth and on interaction with fungal and viral pathogens. Mycorrhiza. 2010;3:191. DOI 10.1007/s00572-009-0279-5.

Firmansyah D., Widodo W., Hendrastuti Hidayat S. Chitosan and Plant Growth Promoting Rhizobacteria Application to Control Squash mosaic virus on Cucumber Plants. Asian J. Plant Pathol. 2017;11:148. DOI 10.3923/ajppaj.2017.148.155.

Harish S., Kavino M., Kumar N., Saravanakumar D., Soorianathasundaram K., Samiyappan R. Biohardening with plant growth promoting rhizosphere and endophytic bacteria induces systemic resistance against Banana bunchy top virus. Appl. Soil Ecol. 2008;39:187. DOI 10.1016/j.apsoil.2007.12.006.

Khalaf E.M., Raizada M.N. Bacterial Seed Endophytes of Domesticated Cucurbits Antagonize Fungal and Oomycete Pathogens Including Powdery Mildew. Front Microbiol. 2018;9:42. DOI 10.3389/fmicb.2018.00042

Lee G.H., Ryu C.-M. Spraying of leaf-colonizing Bacillus amyloliquefaciens protects pepper from Cucumber mosaic virus. Plant Disease. 2016;10:2099. DOI 10.1094/PDIS-03-16-0314-RE. 
Mandadi K.K., Scholthof K.-B.G. Plant Immune Responses Against Viruses: How Does a Virus Cause Disease? Plant Cell. 2013;25:1489. DOI 10.1105/tpc.113.111658.

Moronta-Barrios F., Gionechetti F., Pallavicini A., Marys E., Venturi V. Bacterial Microbiota of Rice Roots: 16S-Based Taxonomic Profiling of Endophytic and Rhizospheric Diversity, Endophytes Isolation and Simplified Endophytic Community. Microorganisms. 2018;6:14.

Muvea A.M., Subramanian S., Maniania N.K., Poehling H.-M., Ekesi S., Meyhöfer R. Endophytic colonization of onions induces resistance against viruliferous thrips and virus replication. front. Plant Sci. 2018;34:73. DOI 10.3389/fpls.2018.01785.

Pakniat-Jahromy A., Behjatnia S.A., Dry I.B., Izadpanah K., Rezaian M.A. A new strategy for generating geminivirus resistant plants using a DNA betasatellite/split barnase construct. Epub 2010;1-2:57. DOI 10.1016/j.jviromet.2010.08.019.

Park C.J., Kim K.J., Shin R., Park J.M., Shin Y.C., Paek K.H. Pathogenesis-related protein 10 isolated from hot pepper functions as a ribonuclease in an antiviral pathway. Plant J. 2004;2:186. DOI 10.1046/j.1365-313X.2003.01951.x.

Paudel D.B., Sanfaçon H. Exploring the Diversity of Mechanisms Associated With Plant Tolerance to Virus Infection. Front. Plant Sci. 2008;9:1575. DOI 10.3389/fpls.2018.01575.

Qi L.S., Larson M.H., Gilbert L.A., Doudna J.A., Weissman J.S., Arkin A.P. et al. Repurposing CRISPR as an RNA-guided platform for sequence-specific control of gene expression. Cell. 2013;5:1173. DOI 10.1016/j.cell.2013.02.022.

Rashid M.H., Chung Y.R. Induction of systemic resistance against insect herbivores in plants by beneficial soil microbes. Front. Plant Sci. 2017:8;1816. DOI 10.3389/fpls.2017.01816.

Ryu C.M., Murphy J.F., Mysore K.S., Kloepper J.W. Plant growthpromoting rhizobacteria systemically protect Arabidopsis thaliana against Cucumber mosaic virus by a salicylic acid and NPR1-independent and jasmonic acid-dependent signaling pathway. Plant $J$. 2004;3:381. DOI 10.1111/j.1365-313X.2004.02142.x.

Sharipova M., Rockstroh A., Balaban N., Mardanova A., Toymentseva A., Tikhonova A., Vologin S., Stashevsky Z. Antiviral Effect of Ribonuclease from Bacillus pumilus against phytopatho- genic RNA-Viruses. Agricultural Sci. 2015;6:1357. DOI 10.4236 as.2015.611130.

Sindarovska Y.R., Guzyk O.I., Yuzvenko L.V., Demchenko O.A., Didenko L.F., Grynevych O.I., Spivak M.Y. Ribonuclease activity of buckwheat plant (Fagopyrum esculentum) cultivars with different sensitivities to buckwheat burn virus. Ukr. Biochem. J. 2014;86:33. PMID: 25033552.

Sugawara T., Trifonova E., Kochetov A., Kanayama Y. Expression of an extracellular ribonuclease gene increases resistance to Cucumber mosaic virus in tobacco. BMC Plant Biol. 2016;3:147. DOI 10.1186/ s12870-016-0928-8.

Trifonova E.A., Ibragimova S.M., Volkova O.A., Shumny V.K., Kochetov A.V. Ribonuclease activity as a new prospective disease resistance marker in potato. Vavilovskii Zhurnal Genetiki i Selektsii $=$ Vavilov Journal of Genetics and Breeding. 2018;8:987. DOI 10.18699/VJ18.441.

Yang S.Y., Lim D.J., Noh M.Y., Kim J.Ch., Kim Y.Ch., Kim I.S. Characterization of biosurfactants as insecticidal metabolites produced by Bacillus subtilis Y9. Entomol. Res. 2017;47:55. DOI 10.1111/1748-5967.12200.

Yang X., Niu L., Zhang W., He H., Yang J., Xing G., Guo D., Zhao Q., Zhong X., Li H., Li Q., Dong Y. Increased multiple virus resistance in transgenic soybean overexpressing the double-strand RNA-specific ribonuclease gene PAC1. Transgenic Res. 2019;28:129. DOI 10.1007/s11248-018-0108-8.

Zhou W., Zhang L., Zhang B., Wang F., Liang Z., Niu T. Isolation and characterization of ZH14 with antiviral activity against Tobacco mosaic virus. Canadian J. Microbiol. 2008;6:441. DOI 10.1139/ W08-026.

Acknowledgements. The work is supported by the joint international granting program of Russian science Fond (RCF) and Department of science and technology (DST) of the Government of India № 19-46-02004.

Conflict of interest. The authors declare no conflict of interest. 